\title{
Electrorotation: A Spectroscopic Imaging Approach to Study the Alterations of the Cytoplasmic Membrane
}

\author{
Adalberto Bonincontro1, Gianfranco Risuleo ${ }^{2 *}$ \\ ${ }^{1}$ Dipartimento di Fisica, Sapienza Università di Roma, Rome, Italy \\ ${ }^{2}$ Dipartimento di Biologia e Biotecnologie, Sapienza Università di Roma, Rome, Italy \\ Email: ${ }^{*}$ Gianfranco.risuleo@uniroma1.it
}

Received 28 October 2014; revised 25 November 2014; accepted 24 December 2014

Copyright (C) 2015 by authors and Scientific Research Publishing Inc.

This work is licensed under the Creative Commons Attribution International License (CC BY).

http://creativecommons.org/licenses/by/4.0/

(c) (i) Open Access

\begin{abstract}
Electrorotation (ER) is a technique allowing the characterization of the surface properties of a variety of supra-molecular aggregates and living cultured cells as well as cellular organelles and biological materials in general. In particular, this technique allows measuring two important physical parameters of the cell membrane: specific capacitance and specific conductance. These parameters are strictly related to the structure/function relationships of the biological membrane; ER becomes thus a powerful means to investigate a number of phenomena involving the membrane integrity. These phenomena may originate from treatments with exogenous molecules and/or from pathological effects. Concerning these aspects, the study of the transfer of exogenous material (i.e. cat-anionic vesicles or liposomes) across the cell membrane assumes a high importance. This review is focused on the physical functioning principles of ER and on the quantitative analysis of the experimental measurements. This work also reports on different fields of application of ER with particular reference to data obtained in our laboratory. The investigation of the alterations of the cytoplasmic membrane function, as evidenced by this strategy, will be illustrated in detail.
\end{abstract}

\section{Keywords}

Electrorotation, Physical Principles, Membrane Dielectric Parameters, Molecular/Cell Biology

\section{Introduction}

The cytoplasmic membrane represents the bio-molecular structure allowing the cytoplasm matrix to communi-

"Corresponding author.

How to cite this paper: Bonincontro, A. and Risuleo, G. (2015) Electrorotation: A Spectroscopic Imaging Approach to Study the Alterations of the Cytoplasmic Membrane. Advances in Molecular Imaging, 5, 1-15.

http://dx.doi.org/10.4236/ami.2015.51001 
cate with the outer world. The transport of substances can be passive or active. In this latter case the cell is forced to expend energy in the process. The membrane is endowed of an intrinsic electrical potential: therefore it works as a highly selective filter. Biological membranes participate to a number of transport mechanisms such as: passive osmosis and diffusion; endocytosis and exocytosis as well as transmembrane protein channels [1].

In the light of what just presented, the membrane integrity plays a fundamental role in a number of cell functions such as metabolism, maintenance of the basal homeostasis and, although in an indirect manner, is also involved in cell differentiation and development. Recently, it has become clear the role of the cell membrane in "filtering" the paracrine apoptogenic and/or intrinsic death signals: therefore the efficient functioning of the cell membrane is essential for cell survival and correct proliferation [for a recent review see: 2 and references therein]. The complexity and multiplicity of the cell membrane is depicted in Figure 1.

Furthermore, the cytoplasmic membrane is primarily implicated in the penetration of exogenous material of the most diverse nature. Entry of this material occurs, just to give two examples, during the processes of gene transfer or drug delivery. Therefore, investigating the integrity and efficiency of the plasma membrane becomes of primary importance: with respect to this, electrorotation represents an excellent tool giving a quantitative idea about the intra-membrane traffic and possible membrane damages. This technique permits, in fact, the characterization of the surface properties of a variety of supra-molecular aggregates in the micrometric size range. The main application of this biophysical methodology is represented by the study of living cells as well as cellular organelles. Since ER allows measuring the two essential parameters of the cell membrane (specific capacitance and conductance), it constitutes a powerful means to investigate a number of phenomena related to the membrane integrity. Considering this particular aspect, it should be pointed out that these parameters are strictly linked to the structure/function relationships of the biological membrane. In addition, one of the major advantages of ER consists in the possibility of carrying out observations on single cells. The measurements are based on the light microscopy analysis of rotating cells in an electric field and take into consideration a sample of cells with respect to their "biological history": metabolic status, dimensions and modes of treatment.

In this review we provide a clear and detailed critical description of the technique and discuss a number of applications to cells subjected to various forms of treatments, such as: exposure to chemicals, viruses and supra-molecular aggregates. The results discussed here refer essentially to data from our laboratory without disregarding the work of other research groups.

\section{Materials}

\subsection{Cell Cultures}

The stable murine fibroblasts 3T6 line was used in all experiments carried out in our laboratories. The cultures were maintained according to routine procedure. Culture medium was DMEM-10\% newborn serum supplemented with glutamine and penicillin-streptomycin. All treatments, with natural substances and liposomes, were performed on cells plated 24 hours earlier. Treatments were continued for 24 hours, if not otherwise specified.

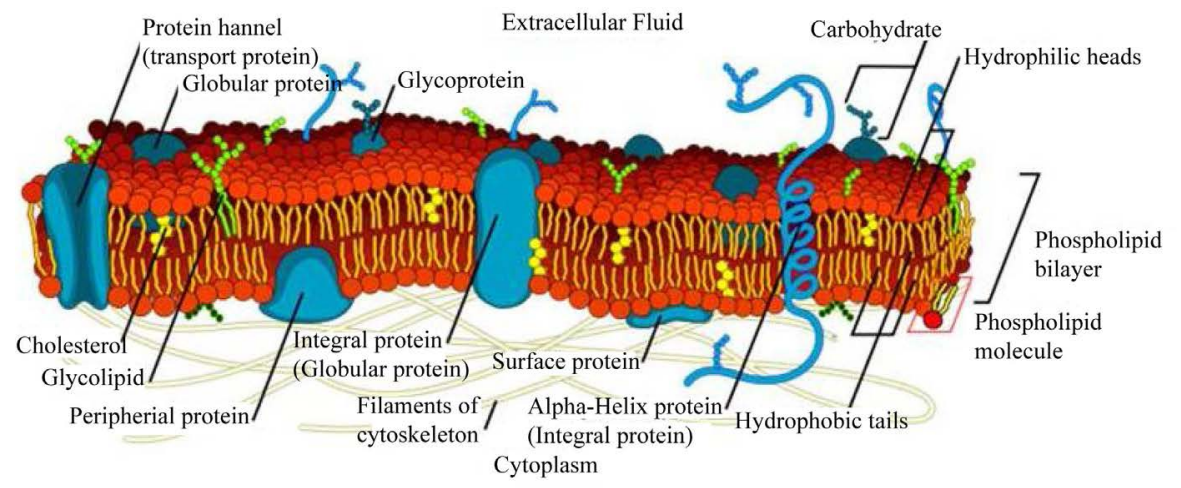

Figure 1. Schematic representation of a typical cell membrane. The image is freely available and not covered by copyright. It was obtained from the www at the following link: https://en.wikipedia.org/wiki/Cell_membrane\#mediaviewer/File:Cell_membrane_detailed_dia gram_en.svg, We acknowledge the work of the original author of this picture: LadyofHats. 
Prior to the electrorotational measurements the cells were trypsinized to detach them from the Petri dish.

\subsection{Cationic Liposome Preparation}

The cationic liposomes used in this work were obtained adding to the zwitterionic phospholipid [1,2-dimyristoyl-sn-glycero-3-phosphocholine, DMPC] the cationic gemini surfactant [(2S,3S)-2,3-dimetoxy-1,4-bis(N,Ndime-thylamine)-butane]. In the text the liposome will be defined as DMPC-G. The aqueous dispersions of liposomes were prepared by extrusion as previously described. For details see [3]-[5].

\section{Electrorotation}

\section{Theory and Experiments}

An electric field, applied to cell suspensions, induces on each single cell an effective dipole moment deriving from the different polarizability between solvent and plasma membrane. The applied electric field used in this technique is rotating to induce a revolution of cells around an axis orthogonal to the direction of the electric field and to the dipole moment. The phenomenon is visualized by a "classical" imaging technique represented by optical microscopy.

In fact, if the mechanism of interfacial polarization is in phase with the electric field, the induced dipole moment is aligned. Increasing the frequency of the field, the polarization mechanism undergoes a phase delay (dielectric relaxation) causing a torque moment and the cells rotate in an anti-field fashion. One should take into consideration that major alterations of the overall structure of the membrane, as in necrotic cells, create an electrical short-circuit at membrane level and the cell ceases to rotate.

This phenomenon is generated in the range of approximately $10^{4}-10^{6} \mathrm{~Hz}$; if the frequency increases further, the electric field traverses the plasma membrane and the sense of rotation is inverted in a co-field fashion. The interface is now between membrane and cytoplasm. In the $\mathrm{kHz}$ range, another relaxation occurs associated to the double electrical layer formed by the counter-ions and the mechanisms of surface conductivity. The formation of the double electrical layer is due to the presence of counter-ions in the proximity of the cell charged surface.

These relaxations are known respectively as $\alpha, \beta$ and $\gamma$ dispersions. However, only the $\beta$ dispersion is directly related to the dielectric properties of the plasma membrane [6] [7]. The rotation period (T) of the cell depends on the frequency $(f)$ of the applied field, according to Equation (1), which describes a Debye-like relaxation:

$$
T(f)=T_{\min } \frac{1+\left(\frac{f}{f^{*}}\right)^{2}}{2\left(\frac{f}{f^{*}}\right)}
$$

where, $f^{*}$ is the relaxation frequency and $T_{\min }$ is the corresponding value of the period. The experimental data must be analyzed by fitting according to Equation (1) to obtain the relaxation frequency. As an example of this analysis, Figure 2 reports the typical dependence of the rotation period by the field frequency of a generic cell suspension in an osmolar sucrose solution. The value of $f^{*}$ appearing in Equation (1) depends on the solvent conductivity according to the expression (2):

$$
f^{*}=\frac{1}{2 \pi R C}\left[\frac{1}{\frac{1}{\sigma_{\mathrm{e}}}+\frac{1}{\sigma_{i}}}+R G\right]
$$

where $C$ and $G$ are, respectively, the specific capacitance and specific conductance of the plasma membrane of a cell with a radius $R, \sigma_{\mathrm{e}}$ is the solvent conductivity and $\sigma_{\mathrm{i}}$ is the conductivity of the cytoplasm considered as homogeneous. Since in general $\sigma_{\mathrm{e}}<<\sigma_{\mathrm{i}}$ Equation (2) becomes:

$$
f^{*}=\left(\frac{1}{\pi R C}\right) \sigma_{e}+\left(\frac{1}{2 \pi C}\right) G
$$

The experimental approach is based on the measurement of the relaxation frequency as a function of the con- 


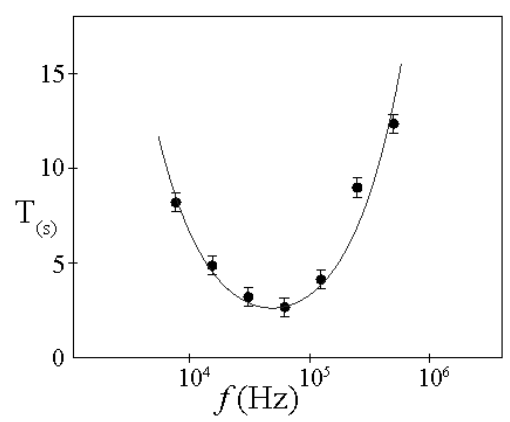

Figure 2. Typical correlation between rotation period of the cell and applied electric frequency. As an example the curve obtained from untreated cells rotating in an osmolar solution. The curve results from the best fit according to Equation (1). The inset shows two typical spheroidal cells in suspension as they appear at optical microscope. The bar is $20 \mu$.

ductivity of the dispersing medium, from which $C$ and $G$ can be calculated by a linear fit taking into account the cell radius. Typically, four dispersing solutions are used: sucrose $300 \mathrm{mM}$ and the same solution supplemented with three $\mathrm{NaCl}$ concentrations: $(0.5 ; 1.0 ; 1.5 \mathrm{mM})$.

The Debye model mimics the cell as a sphere surrounded by a thin homogeneous layer simulating the plasma membrane. In comparison to the complexity of the real biological system, this model is rather coarse; however it proved to be very effective to evaluate even slight changes in the dielectric properties of the cell membrane. The capacitance $C$ is influenced by the biochemical and physical properties of the membrane. The conductance $G$ is informative of the membrane function in terms metabolism/ion-transport. Therefore, this simplified model is commonly accepted as a good tool to investigate the biological membrane conditions [6]-[12].

According to Equation (3) the four relaxation frequencies are dependent on solvent conductivity in a linear fashion: from the slope and the intercept, the plasma membrane parameters $C$ and $G$ can be directly obtained (Figure 3). To have a good statistical estimation of the absolute value of $C$ and $G$, a reasonable number of cells (at least 15) must be taken into consideration. The electro rotation apparatus, used in our laboratory, is implemented with a video-recording system permitting an accurate off-line image analysis [3]. In this way the data acquisition time is considerably shorter, thus avoiding possible artifacts due to cell vitality failure deriving from a prolonged suspension time in sub-optimal conditions.

The rotating electrical field was generated superimposing four square waves out of phase by $90^{\circ}$, with respect to each other. The square pulses were applied to the copper mini-plate electrodes of the measuring cell, which form a central circular cavity with a volume of about $10 \mu \mathrm{l}$ (Figure 4). The whole set up was glued onto a microscope slide. An objective a magnification of $33 \times$ and a focal length of $1 \mathrm{~cm}$ was used. The microscope was connected to a CCD camera producing a further magnification $(20 \times)$.

Following this procedure the values of $C$ and $G$ are obtained with an error margin not lower than $10 \%$. In any case these data must be compared with the one obtained from cells subjected to bio-stresses of various nature. Even though $10 \%$ approximation on a single measurement may seem very large, one should bear in mind that the variations of these parameters with cells exposed to different agents may be very large and far above $10 \%$. The microscopic technique allows also an accurate measurement of the actual cell radius, avoiding the use of average literature data, which may alter the final experimental conclusions.

\section{Overview and Application of Electrorotation in Biological Fields}

The technique of electro rotation is a non-invasive biophysical strategy used to study a vast variety of biological systems such as membrane of prokaryotic and eukaryotic cells subjected to chemical and biological stresses as well as whole organisms, viruses, bacteria and cells [3] [11]-[21]. The electro rotational data are often supported by an additional electrokinetic technique known as dielectrophoresis where non uniform AC electric fields are used to produce a translational motion in charged or uncharged particles [22] [23]. However, the work presented here is specifically devoted to review the main fields of application of the ER strategy. A detailed list of biological systems investigated by ER is reported in Table 1 with the appropriate references. The Table evidences the flexibility of this technique. The subsequent sections of this review will report a recollection of data mainly obtained in our laboratory. 


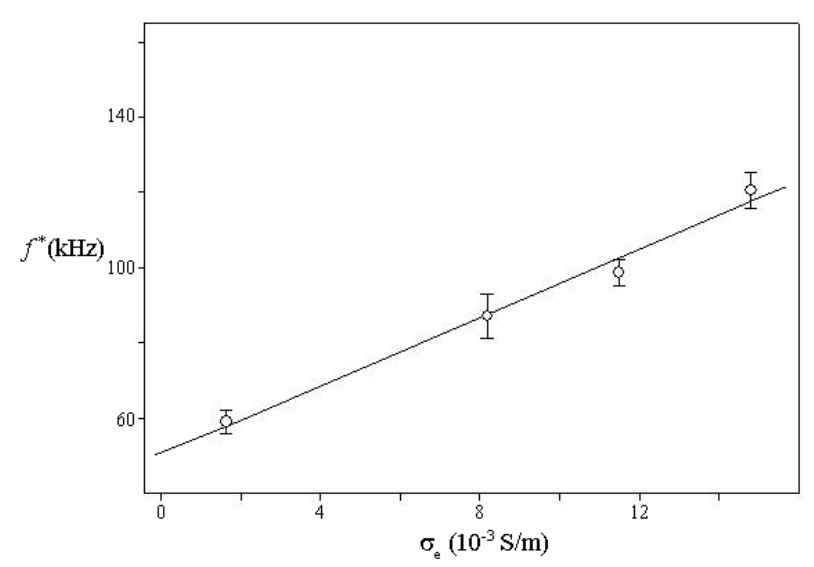

Figure 3. Relaxation frequency $\left(f^{*}\right)$ as a function of the solvent conductivity $\left(\sigma_{\mathrm{e}}\right)$. Experimental data refer to the same sample reported in the legend of Figure 2. The straight line was obtained by a best fit according to Equation (3).

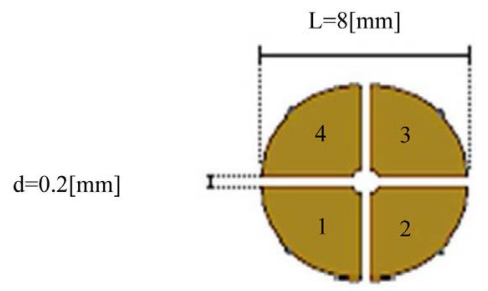

Figure 4. Schematic image of the four-electrode measuring cell. Square waves out of phase by $90^{\circ}$ generate the rotating electrical field. The copper mini-plate electrodes form a central circular cavity of about $10 \mu \mathrm{l}$ and the whole set up is glued onto a microscope.

Table 1. Overview of the main biological systems investigated by electrorotation.

\begin{tabular}{|c|c|}
\hline Experimental models & Appropriate references \\
\hline Viruses, normal, tumor cell and plasma membrane & [3] [8] [13] [17] [24]-[32] \\
\hline Neurospora slime & [9] \\
\hline Biocide treatment & {$[20]$} \\
\hline Plant cells & [21] \\
\hline Flagellar motion in Escherichia coli & [33] \\
\hline Bacterial viability studies, parasites & [11] [34]-[36] \\
\hline Fish embryos & [37] \\
\hline Oocysts of the Cryptosporidium spp. and cysts of Giardia spp. & [18] [38] [39] \\
\hline Green algae $C$. minutum & [40] \\
\hline Lepidoptera insect cells (Spodoptera frugiperda) & [41] \\
\hline Blood cells & [42] [43] \\
\hline
\end{tabular}

In this table, only the application of ER to biological systems is reported; however it should be pointed out that also interaction of synthetic materials, such as latex beads and liposomes, has been investigated.

\section{Effect of Natural Substances of Common Use in Popular Medicine and/or as Dietary Supplements}

\subsection{Semi Purified Methanol Extract of Neem Oil}

Neem oil is a natural mixture obtained from the seeds of Azadirachta indica (A. Juss) known as neem tree. The oil composition is heterogeneous depending upon growth habitat and environmental situation; this oil is normally considered a by-product of more valuable components [44] also as dietary supplements as recently reviewed in [45]. It contains high levels of many organic different compounds. Azadirachtin, possibly the most 
studied component, is a tetra-nor-triterpenoid active as pest and insect control. We prepared a methanol extract of the whole oil defined as MEX which is deprived of the terpenoid/limonoid moiety, and therefore of azadirachtin: we tested its biological properties and effects on cultured cells. The biological effects exhibited by MEX, obviously, are not attributable to azadirachtin but rather to other bio-active molecules whose nature is yet to be fully clarified. In any case, our partially purified mixtures have an anti-proliferative action on cultured mammalian cells and their administration appears to activate the apoptotic pathway [46]. It is commonly accepted by published work that the cell membrane is involved in the progression of the apoptotic death [2 and references therein]. Therefore, it becomes of primary interest the investigation of the membrane biophysical features. To address this specific point we conducted electrorotation experiments on cells treated with MEX. The experimental data were fitted according to Equation (1) to determine the relaxation frequency. Measurements were routinely repeated at different conductivities of the solvent. The relaxation frequencies $f^{*}$ are reported as a function of the solvent conductivity and, as expected from Equation (3), they form a straight line (Figure 5). The average cell radius was estimated on a statistically significant number of cells and the dielectric parameters $C$ and $G$ were calculated (Table 2). While the $C$ value is in good agreement with literature data, a discrepancy in the $G$ value is monitored [47] [48]. This difference is attributable to the fact that fibroblasts are measured in conditions of high viability and proliferation: this may cause a higher intra-membrane ion transport. The results on cells treated with MEX are summarized in Table 2. It is evident that the treatment causes a significant increase of both parameters $C$ and $G$. The increased $C$ value denotes a higher polarizability of the membrane, while the effect on $G$ strongly suggests highly enhanced ion permeability as compared to untreated cells. It should be also pointed out that cells exposed to MEX show a decrease of the radius size. One can speculate that this is principally due to the interaction of the oily moiety of MEX and the fatty component of the membrane: this could promote an overall re-arrangement of the plasma membrane. The alterations of $C$ and $G$ are directly related to this structural modification. Interestingly, these data recall previous results obtained in our laboratory by a different dielectric spectroscopic technique on viral infected and serum deprived cells [49] [50]. The higher polarizability and the enhanced ion permeability are suggestive of an increased membrane fluidity which may end in its damage [51] [52].

A development of this study is represented by the investigation of the effects at membrane level deriving from the infection with murine polyomavirus (Py). The results are discussed in this following section.

\subsection{Virus Infection and Membrane Integrity}

Murine polyomavirus is an extremely well-characterized model system used to investigate a variety of biologi-

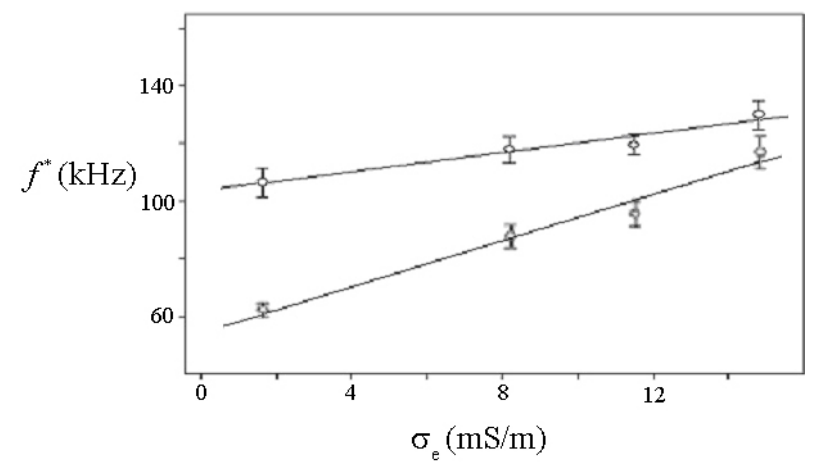

Figure 5. Relaxation frequency $\left(f^{*}\right)$ as a function of the solvent conductivity $\left(\sigma_{\mathrm{e}}\right)$. The straight lines result from the best fit according to Equation (3) in the text. Control cells (lower line); MEX treated cells (upper line). The different slopes and intercepts evidence the effect of the treatment with MEX.

Table 2. Specific capacitance $C$ and specific conductance $G$ and radius $R$ for control (line A) and MEX-treated samples (line B). These values are averaged on 20 different cells. The final concentration of MEX was $5 \mathrm{mg} / \mathrm{ml}$.

\begin{tabular}{cccc}
\hline & $C\left(\mu \mathrm{F} / \mathrm{cm}^{2}\right)$ & $G\left(\mathrm{~S} / \mathrm{cm}^{2}\right)$ & $R(\mu)$ \\
\hline A & $0.9 \pm 0.2$ & $0.3 \pm 0.1$ & $8.2 \pm 0.4$ \\
B & $2.6 \pm 0.6$ & $1.7 \pm 0.5$ & $7.3 \pm 0.4$ \\
\hline
\end{tabular}


cal phenomena: its genome is formed by a small double-stranded circular DNA molecule. Py relies completely on the metabolic machinery of the infected cell. The "classical" book edited by Tooze [53] possibly still represents the most complete work on DNA tumor viruses. In our laboratory, Py has also been used to test the cytotoxic and/or antiviral potential of substances of natural origin [46] [54] [55].

A particular aspect of the productive infection is represented by the virion entry into the cell and by its interaction with the plasma membrane. Information on possible membrane damage consequent to virus penetration is not very abundant, even though reports have been published on the mode and effects of the viral proliferation on the plasma membrane [49] [56]-[58]. The results of electro rotation measurements performed on infected cells show that the viral proliferation induces a relevant increase of both membrane parameters $C$ and $G$. Not surprisingly, this phenomenon is more evident at prolonged times post-infection (Table 3). However if the progression of the infection is reduced in the presence of MEX (Figure 6), which is a specific inhibitor of Py proliferation, the membrane parameters are not altered at the same extent (Table 4). An important observation is that the infection with Py increases significantly the parameter $G$; this indicates an augmentation of the intra-membrane ion transport which reflects an enhanced cell metabolism in response to the viral attack. This idea is also supported by the strong mitogenic action of the virus [53]. In experiments carried out in the presence of MEX, the $C$ value returns to normal levels and also a very strong reduction of the effect on $G$ is monitored. The overall explanation is clearly correlated with the inhibiting action of MEX on the progression of the viral infection.

The data discussed so far show that under a phenomenological point of view both the effect of MEX and the viral infection produce similar modification of the membrane dielectric parameters. Therefore, it becomes very

Table 3. Specific capacitance $C$ and specific conductance $G$ at different infection times with murine polyomavirus.

\begin{tabular}{ccc}
\hline Infection time & $C\left(\mu \mathrm{F} / \mathrm{cm}^{2}\right)$ & $G\left(\mathrm{~S} / \mathrm{cm}^{2}\right)$ \\
\hline Mock infection & $0.8 \pm 0.1$ & $0.26 \pm 0.06$ \\
24 hours & $0.9 \pm 0.1$ & $0.20 \pm 0.04$ \\
48 hours & $1.2 \pm 0.2$ & $0.25 \pm 0.04$ \\
72 hours & $1.3 \pm 0.2$ & $0.45 \pm 0.03$ \\
\hline
\end{tabular}

Table 4. Specific capacitance $C$ and specific conductance $G$ at different times of viral infection in the presence of MEX. The data at 72 hours are omitted since after this time of infection MEX is too toxic to provide reliable data.

\begin{tabular}{ccc}
\hline Infection time & $C\left(\mu \mathrm{F} / \mathrm{cm}^{2}\right)$ & $G\left(\mathrm{~S} / \mathrm{cm}^{2}\right)$ \\
\hline Mock infection & $0.8 \pm 0.1$ & $0.26 \pm 0.06$ \\
24 hours & $0.9 \pm 0.2$ & $0.29 \pm 0.08$ \\
48 hours & $0.8 \pm 0.2$ & $0.34 \pm 0.06$ \\
\hline
\end{tabular}

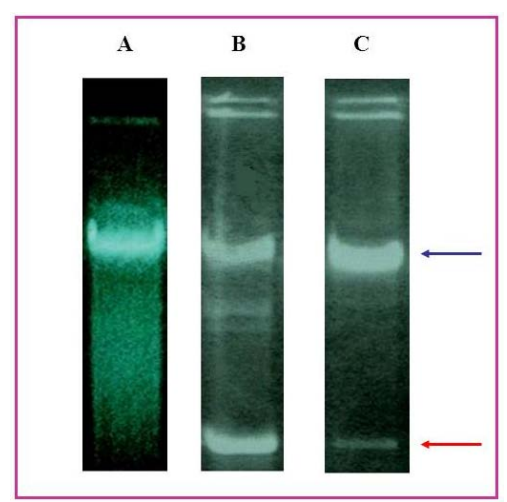

Figure 6. Yield of progeny viral DNA in the control and MEX treated cells. Lane A: Electropherogram obtained from mock-infected control cells; Lane B: Progeny viral DNA yield; Lane C: Progeny viral DNA yield obtained in the presence of MEX. Viral DNA is indicated, when present, by the lower arrow. The higher arrow indicates contaminating cellular chromosomal DNA. 
interesting to analyze the behavior a further natural substance: Resveratrol (RV), endowed with multiple biological actions.

\subsection{Influence of Resveratrol on the Cell Membrane}

Resveratrol is a poly-phenol non flavonoid compound belonging to the family of natural phytoalexins. This molecule is very abundant in red grapes (Vitis vinifera) and in highly pigmented vegetables and fruit such as pumpkin (Curcuma longa) or black mulberry (Morus nigra). The drug shows a great number of diverse biological activities behaving as anti-tumor, antioxidant, phyto-estrogen and antiviral. Its high antioxidant character has been demonstrated in several different situations. The antiviral action of RV has also been demonstrated in several pathological conditions [59]-[69]. The exposure to RV at low dosage does not show a significant cytotoxic effect. At higher doses, on the contrary, it is cytotoxic, possibly due to the fact that this drug is known to induce cell cycle arrest. Moreover, the mitochondrial pathway is activated and this eventually leads to apoptosis [70] [71]. An analogous action has been described for another potent antioxidant: curcumin, which is able to induce apoptosis in human cervical cancer cells [72]. Recent data from our laboratory demonstrate that the drug is promptly assumed by the cell, as shown by the propidium iodide uptake kinetics [31] [73]. We analyzed the action of RV by electro rotation to investigate putative effects on the cell membrane structure/function. The results of these measurements are reported in Table 5. Parallel cytofluorimetric experiments (Figure 7) show the presence of a small sub-population of necrotic cells. It should be kept in mind that these cells do not rotate and therefore are not "visible" by ER: hence they do not give any contribution to the $C$ and $G$ values. We also monitored a small fraction of apoptotic cells. Apoptotic cells do rotate up to a certain stage of the process [13]. However, their number is so small that the contribution to the ER data becomes irrelevant. It is evident (Table 5) that the effect on the two membrane parameters is quite different. After 24 hours of treatment no variation is monitored; while after 48 hours a very small effect on $C$ is observed and, mainly, an evident and large increase of $G$ occurs. Since $C$ is strongly associated to the structure and morphology of the membrane one can conclude that no significant alterations occur. The enhancement of $G$ implies, on the other hand, a dramatic increase of ion
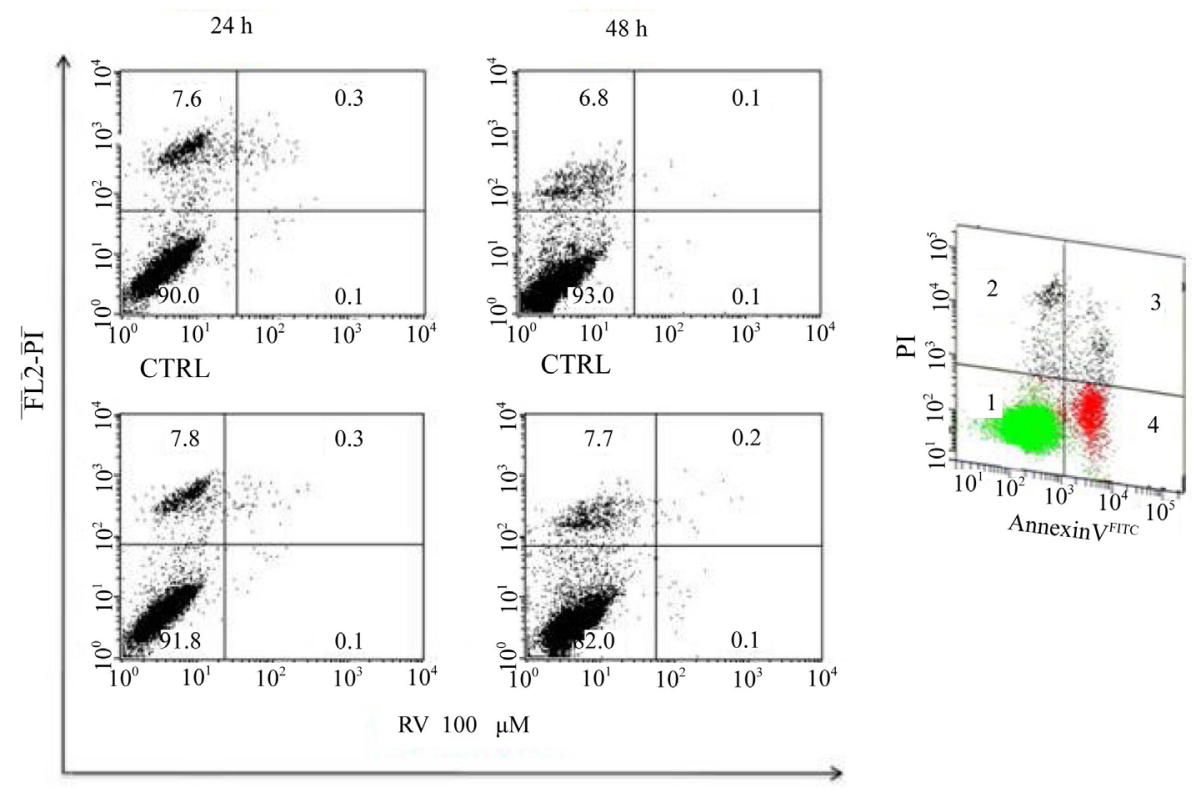

FL1 Annexin V-FITC

Figure 7. Evaluation of apoptosis inducted by RV. Cell surface annexin V binding was studied by flow-cytometry at two different treatment times. At both times of treatment floating and adherent cells were collected and labeled with annexin V-FITC-conjugated. RV concentration, treatment times and percentage of apoptotic and necrotic cells are indicated. The reported values represent the mean of three independent experiments. The smaller panel indicates a schematic and typical cell distribution. Squares 1: Viable cells; 2: Necrotic cells; 3 : Cells in advanced apoptosis; 4: Cells in early apoptosis. 
Table 5. Specific capacitance $C$ and specific conductance $G$ for untreated 3 T6 control and resveratrol treated cells.

\begin{tabular}{ccc}
\hline & $C\left(\mu \mathrm{F} / \mathrm{cm}^{2}\right)$ & $G\left(\mathrm{~S} / \mathrm{cm}^{2}\right)$ \\
\hline Untreated cells (24 hours) & $0.9 \pm 0.1$ & $0.27 \pm 0.03$ \\
RV treated cells (24 hours) & $0.7 \pm 0.1$ & $0.26 \pm 0.03$ \\
Untreated cells (48 hours) & $1.0 \pm 0.1$ & $0.29 \pm 0.04$ \\
RV treated cells (48 hours) & $1.3 \pm 0.1$ & $0.60 \pm 0.06$ \\
\hline
\end{tabular}

transport across the membrane; therefore, the treatment with RV is seemingly associated to an enhanced cell metabolism as observed by other strategies in wholly diverse cell models [see for instance 73].

Electrorotation permits also the evaluation of the consequences at membrane level of supra-molecular aggregates such liposomes and vesicles potential tool for the delivery of "cargo" molecules. This is the topic discussed in the next section.

\subsection{Liposome and Cell Membrane Interactions}

Liposomes are good tools for the delivery of drugs and biomacromolecules [74]. They present many advantages such as biocompatibility, ease of preparation, and high payload capacity. They have been also used as an alternative transfection means to viral vectors. Cationic liposome formulations were shown to be very promising carriers [75]. Liposomes have been shown to feature intrinsic tissue selectivity [76]-[78]. A key step for the biological effectiveness of a liposome formulation is represented by the pathway of intracellular internalization and consequent possible damages at membrane level. The internalization pathway is strongly influenced by diverse parameters, such as: size, shape, rigidity, charge, hydrophobic/hydrophilic balance, presence of specific ligands [79]-[81]. The initial interaction of cationic liposomes with the plasma membrane is of electrostatic nature; however, the general mechanisms of internalization and intracellular trafficking yet remain to be fully clarified. Two main questions of this interaction are represented: first by the adsorption onto the cell surface, followed by the a possible liposome fusion with the membrane. The second question is represented by the internalization into the cell. In addition to electrorotation [3], we also used different experimental approaches to address these issues, i.e. atomic force microscopy (AFM), $\xi$ potential, and laser scanning confocal microscopy (LSCM) as well as biomolecular/cellular techniques [32]. The results of the electrorotation measurements are visualized in Figure 8 which reports the linear trend of relaxation frequency for controls and liposome treated cells. Evident variations of the angular coefficient and intercept, reflecting a decrease of the membrane parameters $C$ and $G$, can be observed unlike what was monitored in the formerly discussed experimental data. Obviously, these differences depend upon the type of interaction and the nature of the exogenous material to which the cell is exposed.

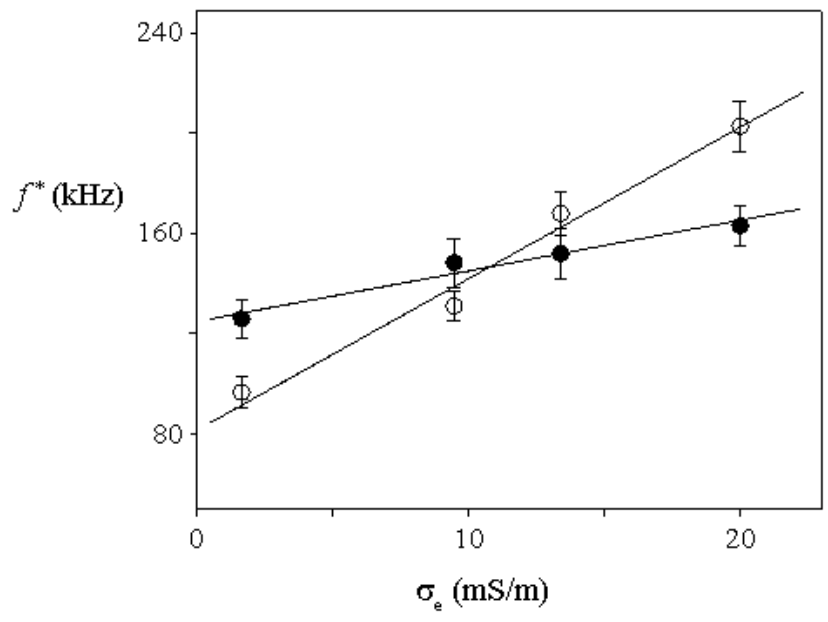

Figure 8. Relaxation frequency $\left(f^{*}\right)$ as a function of the solvent conductivity $\left(\sigma_{\mathrm{e}}\right)$. The full circles refer to untreated control cells. Empty circles report the relaxation frequency of cells treated for 1 hour with DMPC-G liposomes. The straight lines were obtained from each relaxation frequency at the respective ion strength fitted according to Equation (3). 
The percent variations of the membrane parameters and the average cell radius are reported in Table 6. It is worth noting that the cell radius changes significantly as a consequence of the cell/liposome interaction. The decrease of the specific capacitance $C$ may be attributed to different and non-mutually exclusive reasons: thickness and/or decrease of the membrane permittivity $\varepsilon$ ' due to an overall misalignment of the polypeptide moiety; this misalignment implies a variation of the ion transport mechanisms. The increase of cell radius may simply derive from the intracellular liposome uptake; for an extensive discussion of this phenomenon see [3].

The biophysical schematic representation of a cell is usually a sphere surrounded by a thin homogeneous shell, mimicking the plasma membrane [82] [83]. The outer structure of the cell membrane, however, is very different from an ideal smooth sphere. To this end one can adopt a form factor in the expression of the specific capacitance of a spherical condenser [as discussed in detail in the classical treatment reported in reference 10]. In any case, observations conducted by AFM corroborate the data that, interaction with liposomes brings about an overall smoothening of the effective cell surface [32]. Despite the apparent alterations of the membrane parameters discussed above, no evident effect on the overall cell viability is monitored [3].

Electrorotation measurements conducted in the presence of endocytosis inhibitors such as bafilomycin A1 (inhibitor of the vacuolar proton pump) and chlorpromazine (that disrupts clathrin-dependent endocytotic mechanisms) give evidence that liposomes pass through the membrane and are not incorporated into the bi-layer [84]-[86]. In fact, in the presence of the inhibitors the variations of the membrane parameters and the cell radius $R$ are drastically reduced (Table 7). Exposure to the sole endocytosis inhibitors, on the other hand, does not cause changes in the dielectric and geometric parameters of the cell membrane (Table 7, line $C$ ). In addition, measurements of $\zeta$-potential are coherent with the data discussed above [32]. In fact, upon incubation with different concentrations of DMPC-G, the $\zeta$-potential of the cells does not vary. These rules out that liposomes fuse with the plasma membrane. However the conclusive result about the intracellular location of the liposome is evidenced by LSCM of fluorescently labeled particle (Figure 9). Data clearly demonstrate that DMPC-Gs pene-

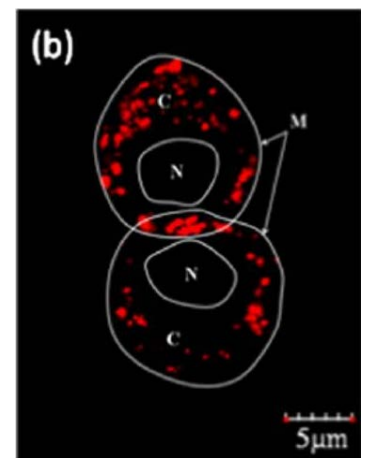

Figure 9. Z-stack confocal image of cells exposed to rhodamine-labeled liposomes. The image shows a single XY slice with two partially overlapping cells. The contour of the cell membrane $(\mathrm{M})$ and of the nucleus $(\mathrm{N})$ is symbolically indicated. It is evident that liposomes are confined to the cytoplasm area $(C)$.

Table 6. The percent variations of the membrane parameters $C$ and $G$ and the average cell radius $R$, for the samples treated for 1 (A) or 4 (B) hours with DMPC-G. The average radius estimated on untreated control cells was $8.5 \pm 0.3 \mu$.

\begin{tabular}{cccc} 
& $\Delta C / C(\%)$ & $\Delta G / G(\%)$ & $R(\mu)$ \\
\hline A & $-70 \pm 7$ & $-71 \pm 6$ & $9.6 \pm 0.4$ \\
B & $-70 \pm 8$ & $-79 \pm 7$ & $9.6 \pm 0.4$ \\
\hline
\end{tabular}

Table 7. The percent variations of the membrane parameters $C$ and $G$ and the average cell radius $R$. (A) Interaction with DMPC-G. (B) Interaction with DMPC-G in presence of endocytosis inhibitors. (C) Effect of endocytosis inhibitors per se.

\begin{tabular}{cccc}
\hline & $\Delta C / C(\%)$ & $\Delta G / G(\%)$ & $R(\mu)$ \\
A & $-70 \pm 7$ & $-71 \pm 6$ & $9.6 \pm 0.4$ \\
B & $-38 \pm 8$ & $-44 \pm 7$ & $8.9 \pm 0.4$ \\
C & $2 \pm 5$ & $5 \pm 4$ & $8.5 \pm 0.4$ \\
\hline
\end{tabular}


trate the plasma membrane and are located only within the cytoplasm.

\section{Conclusive Remarks}

This review article is mainly focused on the great potentials and flexibility of electro rotation. Trypsinization, necessary to detach the cells from the substrate, might actually influence the native membrane parameters. However this is of no consequence regarding the final significance of the measurements since both control and treated cells undergo the same experimental manipulation. Therefore, the final result of the experiment evidences the relative differences between the control and the treated cells. In any case the results are obtained from fully vital cells since non-viable cells do not rotate as discussed in detail. Data obtained by this strategy are summarized but in particular the results of our laboratory are discussed in greater detail. In any case, this review underlines how the synergy between this technique and other imaging and bio-molecular strategies can produce effective and stimulating results. Furthermore, the conclusive consideration is that the multidisciplinary efforts of biochemical-physicists and molecular-cellular biologists can pave the way to fruitful and innovative approaches in the field of life sciences.

\section{References}

[1] Alberts, B., et al. (2012) Molecular Biology of the Cell Garland. 5th Edition, New York.

[2] Mattetti, A. and Risuleo, G. (2014) Apoptosis: A Mode of Cell Death. Biochemistry \& Molecular Biology, 2, 34-39. http://dx.doi.org/10.12966/bmb.09.02.2014

[3] Cosimati, R., Milardi, G.L., Bombelli, C., Bonincontro, A., Bordi, F., Mancini, G. and Risuleo, G. (2013) Interactions of DMPC and DMPC/Gemini Liposomes with the Cell Membrane Investigated by Electrorotation. BBA Biomembranes, 1828, 352-356. http://dx.doi.org/10.1016/j.bbamem.2012.10.021

[4] Hope, M.J., Nayar, R., Mayer, L.D. and Cullis, P.R. (1992) Reduction of Liposomes Size and Preparation of Unilamellar Vesicles by Extrusion Techniques. In: Gregoriadis, G., Ed., Liposome Technology, 2nd Edition, CRC Press, Boca Raton, Vol. I, 123-139.

[5] MacDonald, R.C. and MacDonald, R.I. (1992) Application of Freezing and Thawing in Liposomes Technology. In: Gregoriadis, G., Ed., Liposome Technology, 2nd Edition, Vol. I, CRC Press, Boca Raton, 140-155.

[6] Foster, K.R., Sauer, F.A. and Schwan, H.P. (1992) Electrorotation and Levitation of Cells and Colloidal Particles. Biophysical Journal, 63, 180-190. http://dx.doi.org/10.1016/S0006-3495(92)81588-6

[7] Gimsa, J. (2001) A Comprehensive Approach to Electro-Orientation, Electrodeformation, Dielectrophoresis, and Electrorotation of Ellipsoidal Particles and Biological Cells. Bioelectrochemistry, 54, 23-31. http://dx.doi.org/10.1016/S0302-4598(01)00106-4

[8] Gimsa, J., Pritzen, C. and Donath, E. (1989) Characterisation of Virus-Red Cell Interaction by Electrorotation. Studia Biophysica, 130, 123-131.

[9] Gimsa, J., Marszalek, P., Loewe, U. and Tsong, T.Y. (1991) Dielectrophoresis and Electrorotation of Neurospora Slime and Murine Myeloma Cells. Biophysical Journal, 60, 749-760. http://dx.doi.org/10.1016/S0006-3495(91)82109-9

[10] Wang, X.-B., Huang, Y., Gascoyne, P.R.C., Becker, F.F., Hoelzel, R. and Pethig, R. (1994) Changes in Friend Murine Erythroleukaemia Cell Membranes during Induced Differentiation Determinated by Electrorotation. Biochimica Biophysica Acta, 1193, 330-344. http://dx.doi.org/10.1016/0005-2736(94)90170-8

[11] Dalton, C., Goater, A.D., Burt, J.P.H. and Smith, H.V. (2004) Analysis of Parasites by Electrorotation. Journal of Applied Microbiology, 96, 24-32. http://dx.doi.org/10.1046/j.1365-2672.2003.02113.x

[12] Bonincontro, A., Di Ilio, V., Pedata, O. and Risuleo, G. (2007) Dielectric Properties of the Plasma Membrane of Cultured Murine Fibroblasts Treated with a Nonterpenoid Extract of Azadirachta indica Seeds. Journal Membrane Biology, 215, 75-79. http://dx.doi.org/10.1007/s00232-007-9007-2

[13] Berardi, V., Aiello, C., Bonincontro, A. and Risuleo, G. (2009) Alterations of the Plasma Membrane Caused by Murine Polyomavirus Proliferation: An Electrorotation Study. Journal Membrane Biology, 229, 19-25. http://dx.doi.org/10.1007/s00232-009-9172-6

[14] Georgieva, R., Neu, B., Shilov, V.M., Knippel, E., Budde, A., Latza, R., Donath, E., Kiesewetter, H. and Baumler, H. (1998) Low Frequency Electrorotation of Fixed Red Blood Cells. Biophysical Journal, 74, 2114-2120. http://dx.doi.org/10.1016/S0006-3495(98)77918-4

[15] Huang, Y., Wangi, X.-B., Holzel, R., Beckert, F.F. and Gascoyne, P.R.C. (1995) Electrorotational Studies of the Cytoplasmic Dielectric Properties of Friend Murine Erythroleukaemia Cells. Physical Medical Biology, 40, 1789-1806. 
http://dx.doi.org/10.1088/0031-9155/40/11/002

[16] Hodgson, C.E. and Pethig, R. (1998) Determination of the Viability of Escherichia coli at the Single Organism Level by Electrorotation. Clinical Chemistry, 44, 2049-2051.

[17] Gimsa, J. (1999) New Light Scattering and Field Trapping Methods Access the Internal Electric Structure of Submicron Particles, like Influenza Viruses. Annals of the New York Academy of Sciences, 873, 287-298. http://dx.doi.org/10.1111/j.1749-6632.1999.tb09476.x

[18] Dalton, C., Goater, A.D., Drysdale, J. and Pethig, R. (2001) Parasite Viability by Electrorotation. Colloids and Surfaces A-Physiochemical and Engineering Aspects, 195, 263-268.

[19] Gimsa, J., Pritzen, C. and Donath, E. (1989) Characterisation of Virus-Red Cell Interaction by Electrorotation. Studia Biophysica, 130, 123-131.

[20] Zhou, X.F., Markx, G.H. and Pethig, R. (1996) Effect of Biocide Concentration on Electrorotation Spectra of Yeast Cell. Biochimica Biophysica Acta, 1281, 60-64. http://dx.doi.org/10.1016/0005-2736(96)00015-6

[21] Arnold, W.M. and Zimmermann, U. (1982) Rotating-Field-Induced Rotation and Measurement of the Membrane Capacitance of Single Mesophyll Cells of Avena sativa. Zeitschrift Naturforschung C, 37, 908-915.

[22] Gagnon, Z.R. (2011) Cellular Dielectrophoresis: Applications to the Characterization, Manipulation, Separation and Patterning of Cells. Electrophoresis, 32, 2466-2487. http://dx.doi.org/10.1002/elps.201100060

[23] Pethig, R. (2013) Dielectrophoresis: An Assessment of Its Potential to Aid the Research and Practice of Drug Discovery and Delivery. Advances in Drug Delivery Reviews, 65, 1589-1599. http://dx.doi.org/10.1016/j.addr.2013.09.003

[24] Ziervogel, H., Glaser, R., Schadow, D. and Heymann, S. (1986) Electrorotation of Lymphocytes, the Influence of Membrane Events and Nucleus. Bioscience Reports, 6, 973-982. http://dx.doi.org/10.1007/BF01114974

[25] Gascoyne, P.R.C., Wang, X.-B., Huang, Y. and Becker, F.F. (1997) Dielectrophoretic Separation of Cancer Cells from Blood. IEEE Transactions on Industrial Applications, 33, 670-678. http://dx.doi.org/10.1109/28.585856

[26] Cristofanilli, M., De Gasperis, G., Zhang, L.S., Hung, M.C., Gascoyne, P.R.C. and Hortobagyi, G.N. (2002) Automated Electrorotation to Reveal Dielectric Variations Related to HER-2/neu Overexpression in MCF-7 Sublines. Clinical Cancer Research, 8, 615-619.

[27] Reuss, O.R., Kurschner, M., Dilsky, S., Horbaschek, M., Schenk, W.A., Zimmermann, U. and Sukhorukov, V.L. (2002) Interaction of Fluorinated Lipophilic Ions with the Plasma Membrane of Mammalian Cells Studied by Electrorotation and Dielectrophoresis. Journal of Electrostatics, 56, 419-434. http://dx.doi.org/10.1016/S0304-3886(02)00107-9

[28] Zimmermann, D., Kiesel, M., Terpitz, U., Zhou, A., Reuss, R., Kraus, J., Schenk, W.A., Bamberg, E. and Sukhorukov, V.L. (2008) A Combined Patch-Clamp and Electrorotation Study of the Voltage- and Frequency-Dependent Membrane Capacitance Caused by Structurally Dissimilar Lipophilic Anions. Journal of Membrane Biology, 221, 107-121. http://dx.doi.org/10.1007/s00232-007-9090-4

[29] Sukhorukov, V.L., Imes, D., Woellhaf, M.W., Andronic, J., Kiesel, M., Shirakashi, R., Zimmermann, U. and Zimmermann, H. (2009) Pore Size of Swelling-Activated Channels for Organic Osmolytes in Jurkat Lymphocytes, Probed by Differential Polymer Exclusion. Biochimica Biophysica Acta, 1788, 1841-1850. http://dx.doi.org/10.1016/j.bbamem.2009.06.016

[30] Memmel, S., Sukhorukov, V.L., Höring, M., Westerling, K., Fiedler, V., Katzer, A., Krohne, G., Flentje, M. and Djuzenova, C.S. (2014) Cell Surface Area and Membrane Folding in Glioblastoma Cell Lines Differing in PTEN and p53 Status. PLoS ONE, 31, e87052. http://dx.doi.org/10.1371/journal.pone.0087052

[31] Milardi, G.L., Stringaro, A.R., Colone, M., Bonincontro, A. and Risuleo, G. (2014) The Cell Membrane Is the Main Target of Resveratrol as Shown by Interdisciplinary Biomolecular/Cellular and Biophysical Approaches. Journal of Membrane Biology, 247, 1-8. http://dx.doi.org/10.1007/s00232-013-9604-1

[32] Stefanutti, E., Papacci, F., Sennato, S., Viola, I., Bombelli, C., Bordi, F., Mancini, G., Gigli, G., Bonincontro, A. and Risuleo, G. (2014) Cationic Liposomes DMPC/Gemini Traverse the Cell Membrane and Are Localized within the Cytoplasm without Causing a Significant Bio-Damage. Biochimica Biophysica Acta, 1838, 2646-2655. http://dx.doi.org/10.1016/j.bbamem.2014.05.026

[33] Berry, R.M. and Berg, H.C. (1996) Torque Generated by the Bacterial Flagellar Motor Close to Stall. Biophysical Journal, 71, 3501-3510. http://dx.doi.org/10.1016/S0006-3495(96)79545-0

[34] Dalton, C., Goater, A.D. and Smith, H.V. (2006) Fertilization State of Ascaris suum Determined by Electrorotation. Journal of Helminthology, 80, 25-31. http://dx.doi.org/10.1079/JOH2005326

[35] Gascoyne, P., Pethig, R., Satayavivid, J., Becker, F.F. and Ruchirawat, M. (1997) Dielectrophoretic Detection of Changes in Erythrocyte Membranes Following Malarial Infection. Biochimica et Biophysica Acta: Biomembranes, 1323, 240-252. http://dx.doi.org/10.1016/S0005-2736(96)00191-5

[36] Nascimento, E., Silva, T. and Oliva, A. (2007) Identification, Characterization and Manipulation of Babesia-Bovis-In- 
fected Red Blood Cells Using Microfluidics Technology. Parassitologia, 49, 45-52.

[37] Shirakashi, R., Mischke, M., Fischer, P., Memmel, S., Krohne, G., Fuhr, G.R., Zimmermann, H. and Sukhorukov, V.L. (2012) Changes in the Dielectric Properties of Medaka Fish Embryos during Development, Studied by Electrorotation. Biochemical Biophysisical Research Communication, 428, 127-131. http://dx.doi.org/10.1016/j.bbrc.2012.10.019

[38] Goater, A.D., Burt, J.P.H. and Pethig, R. (1997) A Combined Electrorotation and Travelling Wave Device: Applied to the Concentration and Viability of Cryptosporidium. Journal of Physics D: Applied Physics, 33, L65-L70. http://dx.doi.org/10.1088/0022-3727/30/18/001

[39] Asami, K. and Yonezawa, T. (1996) Dielectric Behaviour of Wild-Type Yeast and Vacuole Deficient Mutant over a Frequency Range of $10 \mathrm{kHz}$ to $10 \mathrm{GHz}$. Biophysical Journal, 71, 2192-2200. http://dx.doi.org/10.1016/S0006-3495(96)79420-1

[40] Reichle, C., Schnelle, T., Müller, T., Leya, T. and Fuhr, G. (2000) A New Microsystem for Automated Electrorotation Measurements Using Laser Tweezers. Biochimica et Biophysica Acta, 1459, 218-229. http://dx.doi.org/10.1016/S0005-2728(00)00150-X

[41] Freitag, R., Schügerl, K., Arnold, W.M. and Zimmermann, U. (1989) The Effect of Osmotic and Mechanical Stress and Enzymatic Digestion on the Electrorotation of Insect Cells (Spodoptera frugiperda). Journal of Biotechnology, 11, 325-336. http://dx.doi.org/10.1016/0168-1656(89)90017-5

[42] Egger, M. and Donath, E. (1995) Electrorotation Measurements of Diamide-Induced Platelet Activation Changes. Biophysical Journal, 68, 364-372. http://dx.doi.org/10.1016/S0006-3495(95)80197-9

[43] Chan, K.L., Morgan, H., Morgan, E., Cameron, I.T. and Thomas, M.R. (2000) Measurements of the Dielectric Properties of Peripheral Blood Mononuclear Cells and Trophoblast Cells Using AC Electrokinetic Techniques. Biochimica et Biophysica Acta, 1500, 313-322. http://dx.doi.org/10.1016/S0925-4439(99)00115-5

[44] Schmutterer, H. (2002) The Neem Tree and Other Meliaceous Plants. Neem Foundation, Mumbai.

[45] Aiello, C., Berardi, V., Ricci, F. and Risuleo, G. (2011) Biological Properties of a Methanolic Extract of Neem Oil, a Natural Oil from the Seeds of the Neem Tree (Azadirachta indica var. A. Juss). In: Preedy, V.R., Watson, R.R. and Patel, V.B., Eds., Nuts \& Seeds in Health and Disease Prevention, Elsevier, London, Burlington and San Diego, 813821.

[46] Di Ilio, V., Pasquariello, N., van der Esch, S.A., Cristofaro, M., Scarsella, G. and Risuleo, G. (2006) Cytotoxic and Antiproliferative Effects Induced by a Non Terpenoid Polar Extract of A. indica Seeds on 3T6 Murine Fibroblasts in Culture. Molecular and Cellular Biochemistry, 287, 69-77. http://dx.doi.org/10.1007/s11010-005-9062-x

[47] Gimsa, J., Schnelle, T., Zechel, G. and Glaser, R. (1994) Dielectric Spectroscopy of Human Erythrocytes: Investigations under the Influence of Nystatin. Biophysical Journal, 66, 1244-1253. http://dx.doi.org/10.1016/S0006-3495(94)80908-7

[48] Cen, E.G., Dalton, D., Li, Y., Adamia, S., Pilarski, L.M. and Kaler, K.V. (2004) A Combined Dielectrophoresis, Traveling Wave Dielectrophoresis and Electrorotation Microchip for the Manipulation and Characterization of Human Malignant Cells. Journal of Microbiological Methods, 58, 387-401. http://dx.doi.org/10.1016/j.mimet.2004.05.002

[49] Bonincontro, A., Iacoangeli, A. and Risuleo, G. (1996) Electrical Conductivity Dispersion as a Probe of Membrane Function after Murine Polyomavirus Infection in Cells in Culture. Bioscience Report, 16, 41-48. http://dx.doi.org/10.1007/BF01201000

[50] Bonincontro, A., Iacoangeli, A., Melucci-Vigo, G. and Risuleo, G. (1997) Apoptosis Dependent Decrease of the Inter-Membrane Ion Traffic in Cultured Mouse Fibroblasts Shown by Conductivity Dispersion. Bioscience Reports, 17, 547-556. http://dx.doi.org/10.1023/A:1027364308147

[51] Cazzola, R., Russo-Volpe, S., Cervato, G. and Cestaro, B. (2003) Biochemical Assessments of Oxidative Stress, Erythrocyte Membrane Fluidity and Antioxidant Status in Professional Soccer Players and Sedentary Controls. European Journal of Clinical Investigations, 33, 924-930. http://dx.doi.org/10.1046/j.1365-2362.2003.01227.x

[52] Ricci, F., Berardi, V. and Risuleo, G. (2008) Differential Cytotoxicity of MEX: A Component of Neem Oil Whose Action Is Exerted at the Cell Membrane Level. Molecules, 14, 122-132. http://dx.doi.org/10.3390/molecules14010122

[53] Tooze, J., Ed. (1982) Molecular Biology of Tumor Viruses: DNA Tumor Viruses. 2nd Edition, Cold Spring Harbor Laboratory Press, Cold Spring Harbor.

[54] Iacoangeli, A., Melucci-Vigo, G. and Risuleo, G. (2000) Mechanism of the Inhibition of Murine Polyomavirus DNA Replication Induced by the Ionophore Monensin. Biochimie, 82, 35-39. http://dx.doi.org/10.1016/S0300-9084(00)00358-8

[55] Campanella, L., Delfini, M., Ercole, P., Iacoangeli, A. and Risuleo, G. (2002) Molecular Characterization and Action of Usnic Acid: A Drug That Inhibits Proliferation of Mouse Polyomavirus in Vitro and Its Main Target Is RNA Transcription. Biochimie, 84, 329-334. http://dx.doi.org/10.1016/S0300-9084(02)01386-X 
[56] Norkin, L.C. (1977) Cell Killing by Simian Virus 40: Impairment of Membrane Formation and Function. Journal of Virology, 21, 872-879.

[57] Drachenberg, C.B., Papadimitriou, J.C., Wali, R., Cubitt, C.L. and Ramos, E. (2003) BK Polyoma Virus Allograft Nephropathy: Ultrastructural Features from Viral Cell Entry to Lysis. American Journal of Transplantation, 3, 13831392. http://dx.doi.org/10.1046/j.1600-6135.2003.00237.x

[58] Damm, E.M. and Pelkmans, L. (2006) Systems Biology of Virus Entry in Mammalian Cells. Cell Microbiology, 8, 1219-1227. http://dx.doi.org/10.1111/j.1462-5822.2006.00745.x

[59] Hosoda, R., Kuno, A., Hori, Y.S., Ohtani, K., Wakamiya, N., Oohiro, A., Hamada, H. and Horio, Y. (2013) Differential Cell-Protective Function of Two Resveratrol(Trans-3,5,4'-trihydroxystilbene) Glucosides against Oxidative Stress. Journal of Pharmacological and Experimental Therapy, 344, 124-132. http://dx.doi.org/10.1124/jpet.112.198937

[60] Biswas, S., Hwang, J.W., Kirkham, P.A. and Rahman, I. (2012) Pharmacologial and Dietary Antioxidant Therapies for Chronic Obstructive Pulmonary Disease. Current Medical Chemistry, 20, 1496-1530.

[61] Li, X.Z., Wei, X., Zhang, C.J., Jin, X.L., Tang, J.J., Fan, G.J. and Zhou, B. (2012) Hypohalous Acid-Mediated Halogenation of Resveratrol and Its Role in Antioxidant and Antimicrobial Activities. Food Chemistry, 135, 1239-1244. http://dx.doi.org/10.1016/j.foodchem.2012.05.043

[62] Ding, D.J., Cao, X.Y., Dai, F., Li, X.Z., Liu, G.Y., Lin, D., Fu, X., Jin, X.L. and Zhou, B. (2012) Synthesis and Antioxidant Activity of Hydroxylated Phenanthrenes as Cis-Restricted Resveratrol Analogues. Food Chemistry, 135, 10111009. http://dx.doi.org/10.1016/j.foodchem.2012.05.074

[63] Olas, B., Zbikowska, H.M., Wachowicz, B., Krajewski, T., Buczynski, A. and Magnuszewska, A. (1999) Inhibitory Effect of Resveratrol on Free Radical Generation in Blood Platelets. Acta Biochimica Polonica, 46, 961-966.

[64] Faith, S.A., Sweet, T.J., Bailey, E., Booth, T. and Docherty, J.J. (2006) Resveratrol Suppresses Nuclear Factor- $\kappa$ B in Herpes Simplex Virus Infected Cells. Antiviral Research, 72, 242-251. http://dx.doi.org/10.1016/j.antiviral.2006.06.011

[65] Palamara, A.T., Nencioni, L., Aquilano, K., De Chiara, G., Hernandez, L., Cozzolino, F., Ciriolo, M.R. and Garaci, E. (2005) Inhibition of Influenza A Virus Replication by Resveratrol. Journal of Infectious Diseases, 191, 1719-1729. http://dx.doi.org/10.1086/429694

[66] Docherty, J.J., Sweet, T.J., Bailey, E., Faith, S.A. and Booth, T. (2006) Resveratrol Inhibition of Varicella-Zoster Virus Replication in Vitro. Antiviral Research, 72, 171-177. http://dx.doi.org/10.1016/j.antiviral.2006.07.004

[67] Clouser, C.L., Chauhan, J., Bess, M.A., Oploo, J.L., Zhou, D., Dimick-Gray, S., Mansky, L.M. and Patterson, S.E. (2012) Anti-HIV-1 Activity of Resveratrol Derivatives and Synergistic Inhibition of HIV-1 by the Combination of Resveratrol and Decitabine. Bioorganic Medical Chemistry Letters, 22, 6642-6646. http://dx.doi.org/10.1016/j.bmcl.2012.08.108

[68] De Leo, A., Arena, G., Lacanna, E., Oliviero, G., Colavita, F. and Mattia, E. (2012) Resveratrol Inhibits Epstein Barr Virus Lytic Cycle in Burkitt's Lymphoma Cells by Affecting Multiple Molecular Targets. Antiviral Research, 15, 196202. http://dx.doi.org/10.1016/j.antiviral.2012.09.003

[69] Campagna, M. and Rivas, C. (2010) Antiviral Activity of Resveratrol. Biochemical Society Transactions, 38, 50-53. http://dx.doi.org/10.1042/BST0380050

[70] Saiko, P., Pemberger, M., Horvath, Z., Savinc, I., Grusch, M., Handler, N., Erker, T., Jaeger, W., Fritzer-Szekeres, M. and Szekeres, T. (2008) Novel Resveratrol Analogs Induce Apoptosis and Cause Cell Cycle Arrest in HT29 Human Colon Cancer Cells: Inhibition of Ribonucleotide Reductase Activity. Oncology Reports, 19, 1621-1626.

[71] Juan, M.E., Wenzel, U., Daniel, H. and Planas, J.M. (2008) Resveratrol Induces Apoptosis through ROS-Dependent Mitochondria Pathway in HT-29 Human Colorectal Carcinoma Cells. Journal of Agricultural and Food Chemistry, 56, 4813-4818. http://dx.doi.org/10.1021/jf800175a

[72] Singh, M. and Singh, N. (2009) Molecular Mechanism of Curcumin Induced Cytotoxicity in Human Cervical Carcinoma Cells. Molecular and Cellular Biochemistry, 325, 107-119. http://dx.doi.org/10.1007/s11010-009-0025-5

[73] Xu, Q. and Si, L.Y. (2012) Resveratrol Role in Cardiovascular and Metabolic Health and Potential Mechanisms of Action. Nutrition Research, 32, 648-658. http://dx.doi.org/10.1016/j.nutres.2012.07.002

[74] Samad, A., Sultana, Y. and Aqil, M. (2007) Liposomal Drug Delivery Systems: An Update Review. Current Drug Delivery, 4, 297-305. http://dx.doi.org/10.2174/156720107782151269

[75] Felgner, P.L., Gadek, T.R., Holm, M., Roman, R., Chan, H.W., Wenz, M., Northrop, J.P., Ringold, G.M. and Danielsen, M. (1987) Lipofection: A Highly Efficient, Lipid-Mediated DNA-Transfection Procedure. Proceedings of the National Academy of Sciences of the United States of America, 84, 7413-7417. http://dx.doi.org/10.1073/pnas.84.21.7413

[76] Dass, C.R. and Choong, P.F.M. (2006) Targeting of Small Molecule Anticancer Drugs to the Tumour and Its Vasculature Using Cationic Liposomes: Lesson from Gene Therapy. Cancer Cell International, 6, 17. 
[77] Dass, C.R. (2003) Improving Anti-Angiogenic Therapy via Selective Delivery of Cationic Liposomes to Tumour Vasculature. International Journal of Pharmacology, 267, 1-12.

[78] Lasic, D.D. (1996) Liposomes in Drug Delivery. In: Rosoff, M., Ed., Vesicles, Marcel Dekker, New York, 447-476.

[79] Allen, T.M., Austin, G.A., Chonn, A., Lin, L. and Lee, K.C. (1991) Uptake of Liposomes by Cultured Mouse Bone Marrow Macrophages: Influence of Liposome Composition and Size. Biochimica Biophysica Acta-Biomembranes, 1061, 56-64.

[80] Heath, T.D., Lopez, N.G. and Papahadjopoulos, D. (1985) The Effects of Liposome Size and Surface Charge on Liposome-Mediated Delivery of Methotrexate-Gamma-Aspartate to Cells in Vitro. Biochimica Biophysica Acta, 820, $74-84$. http://dx.doi.org/10.1016/0005-2736(85)90217-2

[81] Bareford, L.M. and Swaan, P.W. (2007) Endocytic Mechanisms for Targeted Drug Delivery. Advances in Drug Delivery Reviews, 59, 748-758. http://dx.doi.org/10.1016/j.addr.2007.06.008

[82] Pauly, H. and Schwan, H.P. (1959) The Impedance of a Suspension of Spherical Particles Surrounded by a Shell. Zeitschrift Naturforschung, 14b, 125-131.

[83] Asami, K., Takahashi, Y. and Takashima, S. (1989) Dielectric Properties of Mouse Lymphocytes and Erythrocytes. Biochimica et Biophysica Acta, 1010, 49-55. http://dx.doi.org/10.1016/0167-4889(89)90183-3

[84] Marina-Garcia, N., Franchi, L., Kim, Y.G., Hu, Y., Smith, D.E., Boons, G.-J. and Nunez, G. (2009) Clathrin and Dynamin-Dependent Endocytic Pathway Regulates Muramyl Dipeptide Internalization and NOD2 Activation. Journal of Immunology, 182, 4321-4327. http://dx.doi.org/10.4049/jimmunol.0802197

[85] Long, G., Pan, X., Kormelink, R. and Vlak, J.M. (2006) Functional Entry of Baculovirus into Insect and Mammalian Cells Is Dependent on Clathrin-Mediated Endocytosis. Journal of Virology, 80, 8830-8833. http://dx.doi.org/10.1128/JVI.00880-06

[86] Inoue, Y., Tanaka, N., Tanaka, Y., Inoue, S., Morita, K., Zhuang, M., Hattori, T. and Sugamura, K. (2007) Clathrin-Dependent Entry of Severe Acute Respiratory Syndrome Coronavirus into Target Cells Expressing ACE2 with the Cytoplasmic Tail Deleted. Journal of Virology, 281, 8720-8729. 
Scientific Research Publishing (SCIRP) is one of the largest Open Access journal publishers. It is currently publishing more than 200 open access, online, peer-reviewed journals covering a wide range of academic disciplines. SCIRP serves the worldwide academic communities and contributes to the progress and application of science with its publication.

Other selected journals from SCIRP are listed as below. Submit your manuscript to us via either submit@scirp.org or Online Submission Portal.
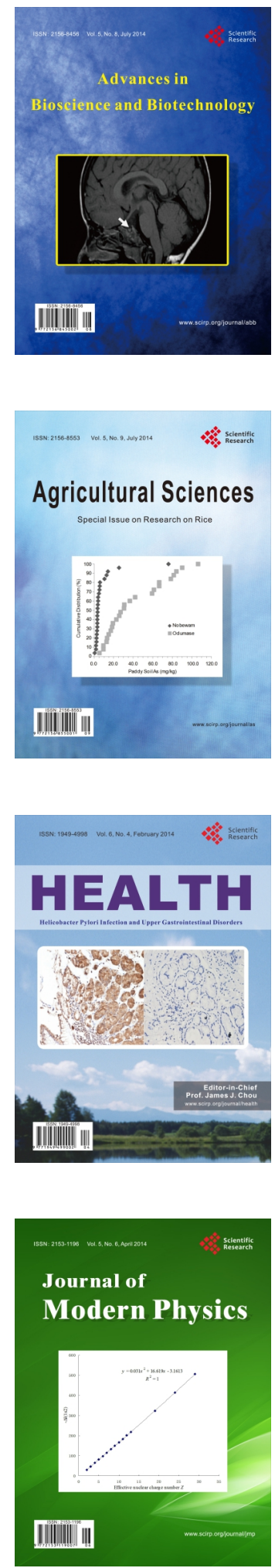
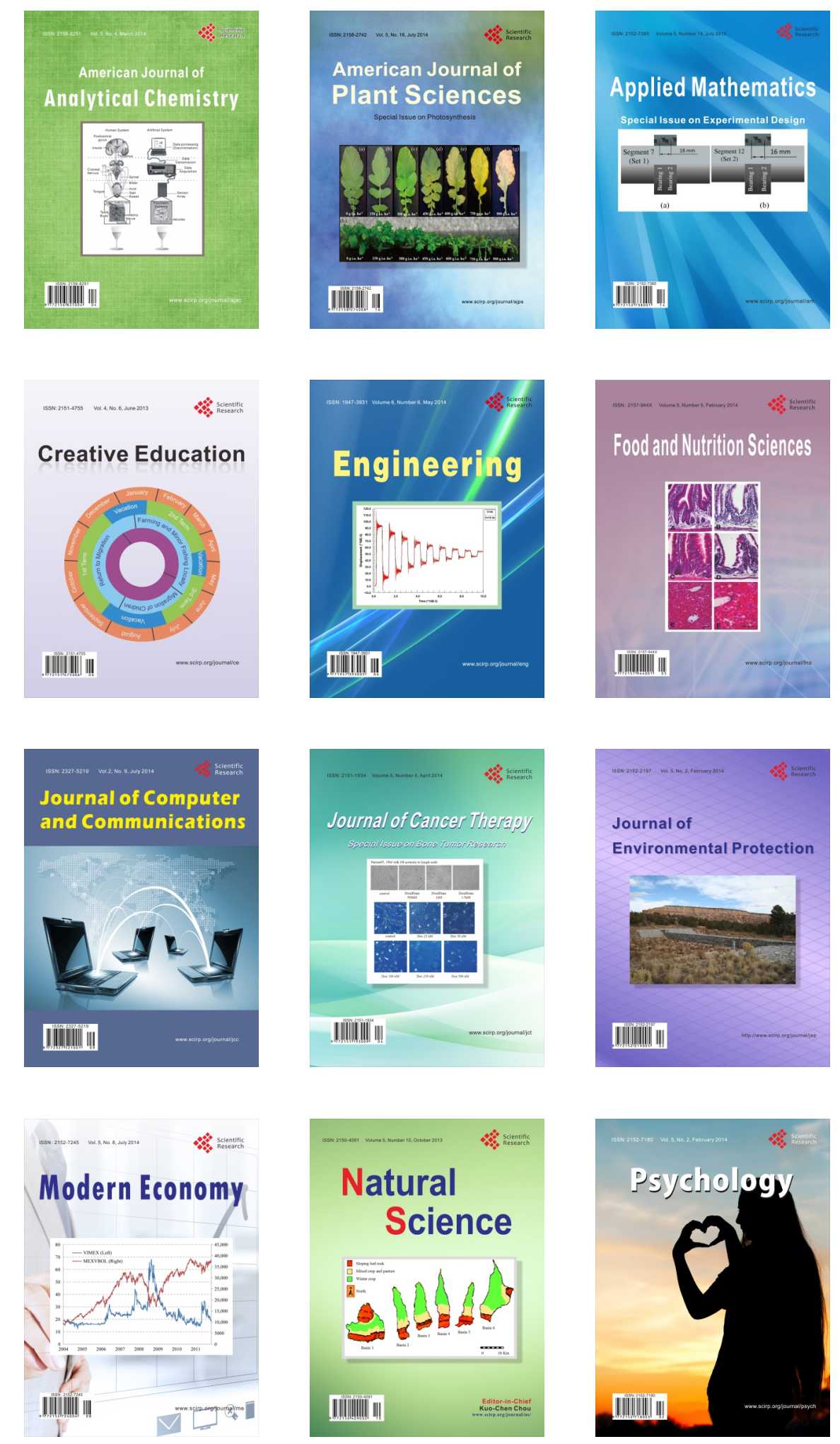